\title{
Research on the marketing electricity side reform strategy of Chinese electricity generation enterprises
}

\author{
Jiwen $\mathrm{Li}^{1}$, a , Weizhe $\mathrm{Tan}^{1}$, Guangbin Zhang ${ }^{1}$ and Ting $\mathrm{Li}^{2}$ \\ ${ }^{1}$ Huadian Power International Corporation Limited ShanDong Branch, Shandong 250014, China; \\ ${ }^{2}$ ShanDong Province Electrical Enterprise Association, Shandong 250101, China; \\ axiangbin_83576305@163.com
}

Keywords:Marketing electricity side reform, electricity generation enterprises, sale of electricity

\begin{abstract}
This article first introduced a new round of power system reform in China, which focusing on the sale of the electric side release strategy and the sale of electricity to carry out business and other direction. Based on the reform and the environment of the energy Internet, the market design ideas and the way to carry out the business of the electricity market are given. Then to create a new way for power generation companies, the challenge and countermeasures for the power generation enterprises to deal with the sale of electricity side are released.
\end{abstract}

\section{Introduction}

In order to further deepen the reform of electric power system, and promote structural adjustment and industrial upgrading, The CPC Central Committee and the State Council issued "some opinions on further deepening the reform of the power system", marking a new round of electricity reform officially launched, which has solved the problems of restricting the scientific development of the power industry.

In the opinions, the reform goal of China's electric power side is to achieve a competitive market, so as to improve the market efficiency and optimize the allocation of resources. To deepen reform of the electricity market and improve the network operation efficiency and service level, the electricity sales side of the market should liberalized gradually in the different stages of development used to adapt the operation ideas. Through the gradual opening of the sale of electricity market, to build a number of main power, let users choose the right to form a multi buyer - Multi seller, the market structure, to build a "open two, regulatory center" industry structure, the establishment of government supervision of the electricity market system, thereby improving the efficiency and service quality, and ultimately to increase the whole social welfare.

At present, the power sale market is being formed, and the operation mechanism is still not perfect, the domestic and foreign electric market are discussed and analyzed by some domestic experts. Some experts believe that if the sale of electricity companies is set up in China, power companies have to overcome the following difficulties, such as legal restrictions, the sale of power quality problems, commodity sources, customer sources, transportation channels, charging, service and other issues, and so on.

Also part of the experts referto foreign mature sale of electricity market, such as American PJM sale of electricity market that in the mature market, the sale of electricity, the sale of electricity to customers may at any time to switch to other electricity sales company, which belongs to the typical with foot voting types of market. At the same time, the experts believes that the sale of electricity in Germany to join the more Internet thinking at the same time, the sale of electricity companies also put forward a lot of green credit as the theme of marketing tools, which to a certain extent has a high reference value for China, compared with China's energy Internet and energy-saving emission reduction strategy.

\section{Ways of carrying out the business of selling electricity}

According to the design idea of the new electric reform, the electric power enterprises should 
improve the design of the electric market; change the mode of operation and the idea of the energy Internet. The release of marketing electricity side for many enterprises which want to participate in the power generation is an opportunity and also a challenge. In order to remain invincible in the fierce competition in the market, power generation companies to do the following.

\subsection{Transform the traditional management idea}

With the electric power market from the "seller" to "buyer", the sale of electricity to the competition needs to transform from the "scramble for resources" to "fight for the user".Power supply in the past tense period, sells the electricity side market is "seller's market", the situation of the power supply is for less than the demand, in peak electricity blackouts, "power shortage" situation occur from time to time to ensure that what users uninterrupted power supply or to which users switch power brownouts and is determined by the sale of electricity department, sale department do not actively compete for the customers.In the development of power industry in the past, the object of competition is power generation resources. And at present our country has already been in the period of excessive redundancy of power generation, the sale of electricity side market once let go, will be out of the "buyer's market", the supply and demand of electricity market is the supply and demand, the sale of electricity sector will face the embarrassment of selling electricity.

Therefore, after the sale of electricity, the competition object transforms from the "fight for power generation resources" into "for power users". This means that the power generation enterprises in the sale of electricity market, it is to change the previous business ideas, to establish a sense of competition, the role of the party from the "party", the focus on the development of what marketing strategy, how to get more power users and to provide users with more quality services, because the market has been to break the pattern of monopoly, so the market has been competitive, the outcome is "survival of the fittest".

\subsection{Reduce electricity prices, improve services}

"Low price" and "high quality service" are the core competitiveness of the customers in the sale of electricity.The sale of electricity department should give users "allowing more profits", then in order to "profit", this is actually a "win-win" strategy.Electricity is a kind of special commodity, a big electricity users if you can reduce the price of a penny, that for the enterprise may reduce billion of costs, this benefit to the user can help the sale of electricity mechanism locks the customers, improve customer viscosity and loyalty.Power generation enterprises sell electricity mechanism for allowing more profits to the user and to avoid the loss of their own interests, the main way is through reducing the power generation cost, operation cost, management cost, which can for the user to provide cheaper electricity can, in order to attract high-quality power users.

In addition to reducing the price of electricity marketing strategy, the other way is to attract customers to provide customers with high quality services.After the sale of electricity market, the sale of electricity as a direct power supply service agencies, power companies to better participate in the competition for the sale of electricity, can gradually expand the scope of business. For example, for power users to provide internal power distribution network update, transformation, and the daily maintenance and other business, and then explore new ways of profit.In addition, combined with the relevant national energy policy, the electricity supply agency to provide users with energy-saving emission reduction, improve efficiency, optimize the load curve and other services to help users improve the efficiency and reduce the power consumption per unit of product, these measures are conducive to improving customer loyalty, forming a virtuous circle.

\subsection{Energy Internet thinking mode}

After the implementation of the electricity, the sale of electricity market will bring a lot of, diverse user service needs (residents, industry, parks, energy-saving low-carbon, etc.), as well as a large number of intelligent terminal access needs (distributed energy, electric vehicles, smart home, energy storage equipment, etc.), only the energy of the Internet to achieve the dynamic balance of energy supply and demand, so as to meet the growing needs of users.

The sale of electricity agencies with a large number of user resources, will become the best access to the energy Internet, electricity agencies should make full use of these resources, in the 
grasp of user needs, with the characteristics of the basis of the design for the user to design a comprehensive energy solutions, to help users use energy, and reduce the cost of users.

\section{Challenge and countermeasures facing the marketing electricity side reform}

\subsection{Challenge facing the marketing electricity side reform}

In the context of the energy Internet, power generation companies to deal with the sale of electricity will face multiple challenges.

(1) Facing with a variety of business types

a) From the traditional power generation to power generation, distribution, power distribution, DSM and other diversified business;

b) From meeting the system load demand to meet the needs of the user's diversification and customization;

c) Comprehensive services from simple energy supply to energy flow and information flow.

(2) Facingthe multi-form market structure

a) From the traditional "generation - transmission - distribution - user" single supply system to the "generation - distribution - user," "generation - sale - user", "generation - user" and other types of coexistence system.

b) From a single horizontal competition (power generation competition) change for horizontal and vertical dimensions competition (transverse power, longitudinal, sale, with many links of competition).

(3) Facing diversified emerging technologies

a) From single to multi type power generation technology, information technology complementary energy;

b) From the traditional centralized power generation technology to distributed generation, energy storage, micro grid technology and centralized power generation technology coordination;

c) From unilateral random fluctuation control technology to supply both stochastic volatility control technology.

\subsection{Countermeasures facing the marketing electricity side reform}

The significance of marketing electricity side reform is by a competitive market mechanism, for users provide more diverse electricity optimization scheme to promote the development of new energy consumptive, energy-saving emission reduction and other.China's power generation companies in response to the sale of electricity can refer to the following response measures.

(1) Three transitions

a) Positioning transition: from the power supply to the starting end of the multi type of energy flow and information flow in the supply side of the supply side

b) Role transition: from power generation to integrated energy suppliers

c) Business transition: from power generation to generation, distribution, electricity and DSM and other diversified business

(2) Three builds

a) Build multi energy power coordinated control platform, which can achieve horizontal multiple complementary energy

b) Build a comprehensive decision-making platform for the sale of electricity, which can simulate and calculate of various types of energy trading prospects and demand potential

c) Build online interactive service platform, which can emphasize the positive interaction between energy supply and users

(3) Three developments

a) Interconnection technology of multi type energy flow and information flow

b) Energy storage technology

c) distributed generation technology

For the future to achieve the horizontal multi energy complementary, vertical source network load storage coordination to provide technical support 


\section{Summary}

In this article, a new round of power system reform in China is introducedfirstly, and focusing on the sale of the electric side release strategy, the sale of electricity to carry out business and other direction. Based on the reform ideas and the environment of the energy Internet, the market design ideas and the way to carry out the business of the electricity market are given. And then the challenge and response measures for the power generation enterprises to deal with the sale of electricity side release, to create a new way for power generation companies to participate in the sale of electricity market competition. The power generation enterprises should carry out the design of the perfect electric market, changes the mode of management thinking, and merges the idea of the energy Internet to make a foothold in the market competition.

\section{Acknowledgements}

This article is supported by the project ${ }^{-}-$research on the marketing management strategy of power enterprises to deal with the electricity side reformof Huadian Power International Corporation Limited ShanDong Branch.

\section{References}

[1]. Wang Zhanbang. The sale of electricity business in the Internet age coming, power system reform bring new power sale thinking. Electro technical: Theory and practice 2015, No. 7: 16-16.

[2]. Bai Yang, Xie Yue, Xia Qing, et al. The system design and the proposed [J]. power system automation, 2015

[3]. Nong Yuan. The depth of interpretation of new electricity reform: the sale of electricity market liberalization will derived 55000000000 [J]. Guangxi electric power, 2015 